\title{
Corrigendum: Evidence for an exceptional twentieth-century slowdown in Atlantic Ocean overturning
}

Stefan Rahmstorf, Jason Box, Georg Feulner, Michael E. Mann, Alexander Robinson, Scott Rutherford and Erik Schaffernicht

Nature Clim. Change 5, 475-480 (2015); published online 23 March 2015; corrected after print 3 September 2015

In the version of this Article originally published, in Fig. 1 the data plotted were for the calendar month of December and not the annual mean data. This has been replaced with a new global temperature trend map for annual mean data, in which (due to the reduced variability of annual as compared with monthly data) the cooling patch in the subpolar North Atlantic stands out even more. The first sentence of the caption for Fig. 1 has been amended to: 'Linear trends of annual surface temperature since AD 1901'. None of the conclusions in the Article are affected by this error. 